\title{
UNA CORTA EXPERIENCIA CON VOCACIÓN DE FUTURO. SIMULACIÓN DE JUICIOS EN LA ASIGNATURA DE DERECHO PROCESAL.
}

\author{
Pilar LASHERAS HERRERO \\ PROFESORA DE DERECHO PROCESAL \\ UNIVERSIDAD DE LA RIOJA \\ Juan de la Cruz OCÓN GARCÍA \\ BECARIO DEL DEPARTAMENTO DE DERECHO \\ UNIVERSIDAD DE LA RIOJA
}

La práctica forense es el elemento básico de la materia a la que se dedica la docencia de esta parte del Derecho, el Derecho Procesal; por ello cualquier acercamiento que el alumno realice a la realidad del foro le permite entender con mayor facilidad la teoría y, a la vez, asentarla de forma más precisa.

La lectura de experiencias similares resultaron de gran ayuda, concretamente las realizadas en Universidad de León y en la de Vigo, asi como los modelos expuestos por el profesor Gimeno Sendra en su libro Practicum de Derecho Procesal, Civil y Penal que fueron el punto de partida de este método de innovación docente que pretende cumplir con las nuevas exigencias de la adaptación al Espacio Europeo de Educación Superior

La actividad consistía en reproducir en el aula un tribunal penal y distribuir entre los alumnos los roles procesales, como acusaciones y como defensas, además de los que formarían parte del órgano judicial, todavía en ese momento, sin concretar.

El grupo de alumnos de ese año habían cursado ya la asignatura de Sistema Judicial Español, en primer curso del Grado universitario, y Derecho Procesal Civil, el cuatrimestre anterior del tercer curso; y demostraban interés por conocer de cerca un proceso jurisdiccional, la mayoría habían acudido al proceso ante un Tribunal de Jurado celebrado en Logroño los meses precedentes.

Se les planteó la actividad tras el estudio de la parte general del proceso penal, estableciendo, en primer lugar, el plan de trabajo junto con los ejercicios que debían ser entregados al finalizar la simulación. Cada uno de los estudiantes prepararía, además de su intervención como parte del proceso, los materiales siguientes:

\footnotetext{
${ }^{\text {I }}$ Gimeno Sendra, V., Practicum de Derecho Procesal, Civil y Penal, Madrid, Editorial Universitaria Ramón Areces, 2007.
} 
- Un expediente judicial, con un modelo de carpetas similar al de cualquier juzgado, que fue repartido en clase, donde se incorporaron algunos de los escritos de las partes y del órgano judicial.

- y un Informe-Resumen que recogiera, al estilo de un informe jurídico, el resultado de todos los trabajos realizados en la práctica judicial y su propia valoración.

El objetivo principal era la participación interactiva de los alumnos desde el principio, es decir, también en el planteamiento del caso; por ello con la ayuda del profesor de Derecho Penal, Sergio Pérez Gónzalez, preparamos un enunciado básico con la descripción de una conducta penal y la intervención de varios participantes:

Una intensa investigación policial descubre una banda que se dedica a robar documentos de identidad de ciudadanos extranjeros (NIE`s), para falsificarlos utilizando la numeración auténtica, y después ser vendidos a otros extranjeros. Añadimos el uso de la escopolamina o burundanga por los miembros de la banda para hacerse con los documentos.

Se expuso a los alumnos como un supuesto abierto que se iría conformando con sus aportaciones, para lo cual debían comenzar a leer sentencias y artículos doctrinales sobre los delitos que se intuían de la descripción anterior. El resto de la sesión se dedicó a conocer los diferentes recursos que ofrece la biblioteca de nuestra Universidad, para que se familiarizaran con todas las bases de datos jurídicas suscritas (Iustel, La Ley Digital, Tirant On Line, Vlex y Westlaw) así como el portal de contenidos bibliográficos Dialnet.

La lectura de las resoluciones judiciales les permitió tener una idea de los tipos penales que afectaban al supuesto de hecho y, sobre todo, vislumbrar aquellos aspectos que, sin figurar todavía en el supuesto, podrían incorporarse para articular, en su momento, el informe final del juicio en sus respectivos roles. Es decir, no se trataba de buscar la solución a los habituales casos prácticos, sino de aportar nuevas circunstancias y datos al enunciado que tras ser aprobados entre todos, les permitieran tener una parte ya definida de su intervención y poder fundamentar, más tarde, tanto las acusaciones como las defensas. De ahí surgió, entre otras, que uno de los acusados padeciera cierto grado de incapacidad mental, o que se incluyera la participación de un funcionario público como cómplice, y así la Abogacía del Estado intervendría como defensa y como acusación.

En las clases siguientes seguimos completando el caso a la vez que se preparaban las pruebas de cada parte (acusación pública, acusación particular, y hasta una acusación popular con una organización que se denominó «Transparencia en democracia»), conseguidas también tras la lectura de sentencias, y que pasaron a formar parte del expediente judicial.

Comenzamos con la creación de un atestado policial, al que se incorporaron pruebas tales como el resultado de una intervención telefónica y el correspondiente auto judicial de autorización, un informe técnico sobre el material de falsificación incautado por la policía tras la detención de los miembros de la banda, y otro toxicológico sobre la escopolamina. El grupo de alumnas que formaban la acusación particular resultó el más activo y ocurrente, y elaboraron la mayoría de las pruebas, llegado a crear un original video de seguimiento a uno de los detenidos, que se aportó como elemento de la instrucción penal. 
Esta parte se simultaneó con las explicaciones teóricas sobre los medios de prueba, por lo que pudimos resolver una serie de cuestiones que, de otro modo, no habrían llegado a plantearse. El aprendizaje del alumno se lograba así a través del método de observación, y con su participación directa en la elaboración del sumario.

En la preparación se fueron siguiendo las fases procesales y cuando quedó cerrada la investigación penal los alumnos elaboraron las resoluciones judiciales procedentes, además de los escritos de calificaciones provisionales que se unieron al expediente. Tras lo cual se procedió a fijar el día para el juicio oral como ejercicio final de esta simulación. En ella intervinieron todos los alumnos, con seriedad y cierta solemnidad, y los que formaban parte del tribunal, vistiendo la preceptiva toga negra, dirigieron el desarrollo de la vista y participaron con alguna precisión. Se siguió el orden habitual en los juicios, aunque quedaron reducidas a la parte de los informes finales, en cuya elaboración fue decisiva, de nuevo, la ayuda de los profesores del Área de Derecho Penal.

El resultado final fue muy positivo, y puede resumirse con la conclusión de un alumno que terminaba su Informe-resumen «...descubrí mientras estudiaba para el examen de la asignatura que la simulación de juicio me había servido mucho más de lo que creía». En definitiva, trabajando y preparando el expediente judicial y el informe final del juicio había logrado diferenciar fácilmente los conceptos procesales, y situarlos en las fases correspondientes del proceso penal.

La entusiasta y efectiva participación de todos los alumnos permitió, también, superar los inconvenientes de una experiencia novedosa y con buen humor se terminaban las discusiones de los que tuvieron que defender «tesis perdedoras» frente a las «ganadoras».

Y la continuidad de esta practica parece garantizada, en nuestra universidad, a través del Proyecto de investigación «Formación para la abogacía: procesos judiciales y procedimientos de mediación simulados», que desde el Área de Derecho Procesal dirige el catedrático de la asignatura, D. Pedro $\mathrm{M}^{\mathrm{a}}$ Garciandía González.

\section{Bibliografía}

CARRERAS BARNÉS, J., «Competencias y planes de estudios» en El debate sobre las competencias en la enseñanza universitaria, Octaedro, Cuadernos de docencia universitaria, núm. 5, Universidad de Barcelona, 2008, (disponible en http://www.octaedro.com/ice/pdf/5CUADERNO.pdf; fecha de consulta: I5.II.20I3).

GARCIMARTín, R., GUtiéRreZ, Ma. R., Y MARTíneZ, C., «La práctica forense como instrumento docente en la enseñanza del Derecho procesal» en PiCó I Junoy, J., (Dir.), El aprendizaje del Derecho Procesal: nuevos retos de la enseñanza universitaria, Barcelona, Editorial Bosch, $201 \mathrm{I}$.

Gimeno Sendra, V., Practicum de Derecho Procesal, Civil y Penal, Madrid, Editorial Universitaria Ramón Areces, 2007.

GonzÁlez Granada, P., «Acción pedagógica de simulación de juicios. Metodología docente de Derecho Procesal en el EEES», Revista Jurídica de Investigación e Innovación Educativa, REJIE, núm.2, Universidad de Málaga, 20I0, pp. 8I-92 (disponible en http://www.eumed.net/rev/rejie; fecha de consulta: I5.II.2OI3).

GonZAlez Pillado, E. «Una experiencia en la docencia del practicum de Derecho Procesal», Revista de formación e innovación educativa universitaria, vol. 2, Universidad de Vigo, 2009. 